\title{
Research on the Application of Accounts Receivable Financing
}

\author{
Jiaxin PEI \\ The School of Accounting, Capital University of Economics and Business, Beijing, China \\ 1433262830@qq.com
}

\begin{abstract}
This paper analyzes the current status of SMEs concerning financing difficulties, and focuses on the application of accounts receivable financing to assist the development of the enterprises. After briefly introducing accounts receivable financing, its current development at home and abroad, the classification and characteristics of SMEs in China and the reasons of their difficulties in financing, the paper has discussed possibility to solve the problem by adopting accounts receivable financing and the potential risks. The author also deals with the simulated process of accounts receivable financing by one particular SME and conclude the outlook of accounts receivable financing considering the impact of the COVID-19.
\end{abstract}

Keywords: Accounts receivable financing, SMEs, Credit, Operating risk, Loans

\section{INTRODUCTION}

At present, some scholars in China have studied the financing methods of accounts receivable, and made assumption and simulated application of accounts receivable financing by modelling a company's operation and building a virtual system of production and procurement.

Secondly, by studying the methods and characteristics of accounts receivable financing, some researchers pointed out the reasons behind possible adverse selection of accounts receivable financing, and put forward some effective solutions, such as supply chain finance, which provides reference for the commercial banks in China to do business with SMEs having accounts receivable as pledge for loan.

Thirdly, some studies have put forward new thinking on the financing difficulties of SMEs. With the continuous development and improvement of China's market economy system, a large number of SMEs have gradually become an indispensable and important force in the social and economic development. However, their financing ability has been hindered to some extent. Different from large enterprises, SMEs are less competent and have limited access to affordable loans. Therefore, some domestic scholars think that SMEs generally have a certain amount of accounts receivable, and that reasonable use of these accounts receivable can become a way of financing. 1

Additionally, the paper is written amid the critical stage of the prevention and control of COVID-19 in China. The epidemic has caused a non-negligible impact on the operation of domestic enterprises of all sizes, especially SMEs. In Chapter 6, this paper will analyze the financing situation of enterprises during the epidemic, and make further analysis on the impact of the epidemic on future accounts receivable financing.

\section{DISCUSSION AND ANALYSIS OF RELEVANT CONCEPTS OF ACCOUNTS RECEIVABLE FINANCING}

\subsection{Connotation and characteristics of accounts receivable financing}

Accounts receivable financing usually refers to a financing method in which an enterprise uses its accounts receivable, which were created when a company let a buyer purchase their goods or services on credit, to get financing capital from a specialized financing institution. The institution will help with the cash flow of the enterprise and provide with one or multiple financial services such as financing, debt collections, sales account 
management, credit sales control and full protection against bad debts and more. 2

At present, the imperfect laws and regulations concerning accounts receivable financing in our country fail to create favorable conditions for promotion in various industries. Under the circumstances, the number of enterprises adopting this financing method is very limited, and the results are not satisfactory. 3

Accounts receivable financing can be divided into three categories by the fact that whether there is a substantial transfer of risk and reward: Accounts receivable pledge financing, factoring and financing securitization.

Accounts receivable pledge financing refers to the financing method in which an enterprise signs a contract with banks and other financial institutions, takes its accounts receivable as a pledge, and accesses short-term loans immediately within limited time span and under certain limited conditions specified in the contract. 4

Factoring is a financing solution that helps enterprises obtain funds by transferring its legally-owned accounts receivable to the bank, while the enterprises still own the liabilities for the due payment of the accounts receivable from the buyer, and also undertake the responsibility of repurchasing of the accounts receivable at the request of factoring bank

Financing securitization is a process by which enterprises transfer financing from bank loans to debt instruments of liquidity, such as bonds, in which fundraisers directly raise funds from the public in the securities market by issuing various securities, stocks and other commercial papers. 5

\subsection{Analysis of the current situation of accounts receivable financing in China}

On December 31,2013, the accounts receivable financing service platform (hereinafter referred to as the platform) launched by the Credit Reference Center of the People's Bank of China was put into trial operation, and was vigorously promoted and used nationwide. The platform serves for accounts receivable financing. By providing services of information and cooperation for involved creditors, debtors and fund providers and more, the platform promotes more accounts receivable, attracts more institutions to participate in financing, solves the financing difficulties of many enterprises, and improves market efficiency.
Although China has put some emphasis on and built relevant infrastructure for accounts receivable financing, the progress in various regions has been quite uneven. In economically developed provinces, such as Jiangsu, Zhejiang, Anhui, etc., the popularity of accounts receivable financing business is higher than that in relatively less developed regions. Overall, the popularity of accounts receivable financing business in the south is higher than that in the north. 6

\section{ANALYSIS OF THE FINANCING STATUS OF SMES IN CHINA}

\subsection{Definition and characteristics of SMEs}

\subsubsection{Definition}

Small-and-medium-sized enterprises are broad in concept and can be divided into three categories, namely, medium-sized enterprises, small enterprises and micro enterprises. Compared with large enterprises, the total assets, turnover and number of employees of these enterprises are lower and occupy a smaller market share. However, the definition of small and medium-sized enterprises in Economics is not limited to the capital situation, but lies in its impact on the whole market economy, and according to the impact of the degree of small and medium-sized enterprises classified.

Nowadays, with the rapid development of market economy, the comprehensive strength of an enterprise cannot be measured by its size alone. For labor-intensive enterprises, such as the production workshop that mainly relies on manpower, the scale of the workshop has a great impact on the core competitiveness of the enterprise; however, for technology-intensive enterprises, due to the high-tech and innovative talents, small-scaled enterprises can also be more influential and occupy a bigger market share by virtue of automation and innovative technology.7

Therefore, considering factors such as scale and development in science and technology, the definition of SMEs can be regarded as follows: Small and mediumsized enterprises (SMEs) refer to the economic subjects with insufficient competitiveness, lower level of technological development, poorer level of innovation, lower utilization rate of resources and poorer products in industry. 


\subsubsection{Features}

\subsubsection{Small scale}

Compared with well-established large enterprises, the SMEs that were found and built by several people or even one person have insufficient original capital, less cash flow and more short-term liabilities, which brings high liability-on-asset ratio, great repayment pressure, and much risk towards enterprise operation. Meanwhile, inadequate capital accumulation limits the prospects of SMEs who, despite their desire to innovate, cannot access sufficient resources to invest in research as large enterprises. There are many obstacles in greatly improving the comprehensive competitiveness of SMEs.

\subsubsection{Financing difficulties}

There are many financing channels for enterprises, mainly including four types, which are: Issuing shares, issuing bonds, bank loans and private financing. First of all, the threshold of bank loan is relatively low, which makes it the main way for SMEs to finance. In addition, compared with banks, the securities market is more difficult for SMEs to enter with as strictly high standards as listed companies. A lack of sufficient policy support makes it difficult for SMEs to obtain financing through the capital market. Moreover, private financing brings larger risks and greater pressure on repayment, so SMEs are less likely to take this financing method. However, having compared the four methods, it seems that bank loans could be the best choice for SMEs. Whereas, by bank loans, the companies have relatively limited access to funds, and usually need to repay in a short period, which means greater pressure and certain limitation on their business operation. To sum up, SMEs have always been faced with the limited access to affordable funds. 8

\subsection{Study on the causes of financing difficulties for SMES}

\subsubsection{Weak repayment ability and high operating risk}

China's SMEs are mostly privately-owned, whose insufficient funds cause weak repayment ability. SMEs do not have a scientific and rigorous system and face lax internal management and unpleasant business. Once the customers of such enterprises fail to repay the accounts payable in time, and the enterprises are in urgent need of cash, they are likely to fall into crisis, become difficult with their capital, and even face the risk of bankruptcy. In the matter of financing, repayment ability is one of the most important factors, especially in the eyes of banks and other financial institutions. Whether the enterprises have enough repayment ability, to a large extent, determines their success of getting loans.9

\subsubsection{Strict requirement of credits}

The credit of an enterprise is very important, and a good one can favor the expectation of investors, banks and other institutions so that they are more willing to approve the loans and then solve financial problems of the enterprise. However, some SMEs in China fail to pay attention to their credits, even evade taxes and cheat consumers, which lets banks and other financial institutions spot the lack of integrity of enterprises under scrutiny, and thus refuse to loan. 10

\subsubsection{Information asymmetry}

The information asymmetry between SMEs and major financial institutions in China hinders the financing of SMEs, because financial institutions need to comprehensively evaluate their solvency, operation, credits, customer sources and other aspects through meticulous investigation and analysis. The institutions also need to increase the interest rate of the loan to minimize the risk of non-profit margin. However, SMEs have weak repayment ability and insufficient capital, so when confronted with loans with high interest, they need to make risky investments with higher returns, which represents a challenge to the survival of enterprises. Therefore, in order to avoid the risks brought by high interest rates, many enterprises can only choose not to loan or finance. 11

\subsubsection{A lack of policy support}

First of all, large enterprises are often preferred in bank loans, securities issuance or private loans by virtue of leading science and technology, abundant capital and bright prospects. Then large enterprises can invest more resources in products for upgrading and further improve their core competitiveness, making large amount of financing easier. Over time, large enterprises develop better and create an upward spiral. However, SMEs are weak and slow in preliminary development. If they could not get supported by policies, such as tax reduction and increased subsidies, their financing will only deteriorate. Although China has given some aids to SMEs, but the standardization is poorly maintained. Many policies are 
only superficially laid out without helping SMEs cope with financing difficulties. 1213

\subsection{Solutions to financing difficulties of SMEs}

\subsubsection{Improving the financing system for SMEs}

First of all, in order to support the development of SMEs, China has issued a series of important policies to help guide their development. However, the legal system in this regard is still essentially defective without sufficient, targeted, systematic and practicable solutions. Therefore, our country can plan practicable policies in details considering the grass-roots' benefits and feasibility, and further clarify the legal position of SMEs in their industries, so as to protect them to get fair access to funds and development opportunities. At the same time, our country can build supervision institutions to report the implementation and effect of policies to the supervising authorities at all times, make overall planning and solve the financing difficulties of SMEs. 14

\subsubsection{Accelerating the built-up of credit system for SMEs}

Information asymmetry is one of the important reasons that hinders the financing of SMEs. In order to guarantee an easy, affordable and quick access to information, our country can improve the social credit system. On the one hand, it is necessary to perfect the legal system of information disclosure of SMEs, and build an open and transparent platform for unimpeded flow of information through legislation so as to improve the transparency of SMEs; on the other hand, it is needed to set up relevant management departments to thoroughly collect and sort out the information in the platform, and build an information disclosure system covering SMEs in all walks of life nationwide. 15

\section{ANALYSIS OF ACCOUNTS RECEIVABLE FINANCING FROM ALL DIRECTIONS}

\subsection{Conditions for enterprises approaching accounts receivable financing}

Although accounts receivable financing can support SMEs in various industries to a certain extent and provide a brand-new financing channel, this method cannot be applied to all enterprises.
First of all, the creditors of accounts receivable, that is, the enterprises that need financing, need to be scaled ones with good credits and strong core competitiveness. In addition, due to the asymmetry of information, enterprises are required to disclose important information, including but not limited to tax registration certificates, tax records, business licenses, financial statements and audit reports for the past three years.

Secondly, the debtors of accounts receivable, that is, the purchasers of enterprises' products and service or more, need to have stable solvency. The payments of accounts receivable are generally due within 90 days, and the ones within 30 days make an enterprise the optimal option. In addition, the creditors of accounts receivable should avoid dealing with only one or a few debtors. In this case, once the debtor defaults, the bank may have to bear huge risks, and thus could reject the enterprise's accounts receivable as pledge for financing. 1617

\subsection{Risk analysis of accounts receivable financing concerning enterprises, customers and investors}

\subsubsection{Enterprise}

Enterprises may face operational risks after financing with banks and other financial institutions through accounts receivable. When the financing transaction starts, the creditor of the accounts receivable, that is, the enterprise, is the first for the repayment, and must pay off the financing funds in due time. However, if the debtor suffers disruptive changes with broken capital chain, or even maliciously escapes the debt, and the enterprise cannot collect the debt within a short time, or even let it turn into bad debt, the financing pledged by the accounts receivable will encounter risks as well as the credit of the enterprise. 18

Additionally, enterprises may also face the risk brought by counterplead rights. According to the contract, the creditor (enterprise) needs to send a batch of goods or provide certain services to the debtor (customer). If the goods and services cannot be provided within the time limit agreed in the contract due to the problem of the enterprise's production chain or the shortage of raw materials, the debtor of the accounts receivable has the right of counterplead and refuses to pay, thus causing the creditor (enterprise) to send the products again or leaving the deal as bad debts. Therefore, as a kind of pledge, accounts receivable do not have the same stability as real 
estate, fixed assets and so on. If the creditor suffers greater risks, failing to realize creditor's rights, a successful cooperation between enterprises and banks and other financial institutions will be less likely to come true.

\subsubsection{Customer}

Customers refer to the buyers of products produced by enterprises, the objects of service by service companies and more. In this case, they are the debtors of accounts receivable. In order to repay the financing funds as soon as possible, some enterprises, regardless of the quality, produce unqualified products in large quantities and mix them with qualified products before sending the goods. If the customers fail to closely check the quality and quantity of the goods and pay directly, they are likely to suffer losses.

\subsubsection{Investors}

The investor refers to the bank and other financial institutions that provide financing for enterprises. First, banks may face the risk caused by the right of set-off. The rights of set-off refer to the rights that both parties to the accounts receivable enjoy when agreeing on the legal setoff of debts. China's law has no exact constraint of the time on the right of set-off, so both the creditor and the debtor can exercise the right at any time. Although it is beneficial to both ends, the authenticity of the accounts receivable is difficult to guarantee, and there is no guarantee to take it as a pledge. 19

In addition, investors may face the risk of fraud. In the matter of accounts receivable financing, in order to reduce the risk of "wasting money," banks and other financial institutions will conduct a rigorous and comprehensive review of the enterprise, and financial statements are one of the key aspects. If the data of financial statements are good, then investors are more likely to fund the company. The investors' stress on the financial statements makes many enterprises add trumped-up transactions in the accounts and whitewash the statements in order to obtain financing; or fabricate increased amount of accounts receivable; or disperse debtors of the accounts receivable from individual into multiple people so as to reduce the risk; or register the unqualified accounts receivable that have been posted into the qualified accounts receivable yet to be posted, so as to avoid or reduce the loss of registered bad debts. All these may make investors have wrong judgments, and then may complete extremely high-risk financing activities.2021

\subsection{Impact of accounts receivable financing on the financial order and market structure}

\subsubsection{Financial order}

Financial order refers to the legal order under the laws and regulations concerning financing, including the issuance and trading order of stocks, bonds and funds, the insurance management order, the credit order and the private loan order. In terms of credit order and private loan order, due to the promotion of accounts receivable financing, it is likely to set strict demands on the accounts receivable's time limit, amount, number of debtors, conditions of using offset rights and even the quality of products and services so as to legalize accounts receivable pledge financing, institutional and systematic and minimize the risks borne by enterprises, customers and investors. In addition, besides accounts receivable as pledge of financing, other assets as pledge will also embrace improved review system, so that the loan transactions are more safe, orderly, open and transparent. 22

\subsubsection{Market structure}

The market structure refers to the position and mutual relationship between the buyer and the seller in the exchange activities in the market economy. The appearance of this position and relationship depends on the supply and demand of commodities in the market. In many cases, the price of products is not determined by the value of products, but by the relationship between supply and demand of products. Accounts receivable financing provides a lower threshold for financing for many SMEs, so that they could see progress in assets, resources, talent introduction and other aspects, then promote the innovation and upgrading of products, and put highquality products with good effects into the market. By doing this, the existing market will shape its competitive atmosphere with competing products and substitutes rushing in, products and consumers' choices getting enriched, and the market economy becoming healthier. 23 


\section{Model OF Simulated ACCOUNTS RECEIVABLE FINANCING OF Q ENTERPRISE}

\subsection{Profile of $Q$ enterprise}

Q enterprise is a private enterprise established in 2010 , mainly engaged in the production and sales of intelligent household appliances. The enterprise is fund and built by only five people with a registered capital of 15 million yuan. It is small in scale, poor in brand influence and low in sales. There are various quality competitive products of other brands in the same industry, bringing great operating pressure. In all, $\mathrm{Q}$ enterprise belongs to the scope of SMEs with lesser debt.

\subsection{Financing of $Q$ enterprise}

\subsubsection{Status of internal financing}

Q enterprise was established in early 2010, and was in its infant stage. Therefore, it has adopted a conservative business strategy, focusing on optimizing the production workshop, and is not eager to expand production. Thanks to its stable operation, excellent product quality and broad scope of target customers, Q enterprise has accumulated a certain amount of capital, and then continued to invest and expand production, but has not invested much more resources to innovate and upgrade its products. In the past three years, with fiercer market competition, the continuous expansion of production, and the increasing financing demand, the enterprise has less sufficient funds to meet its needs of development and profit, and may face the risk of loss when the competitive products of other companies in the same industry flood into the market.

Table 1: Cash flow of Q enterprise from 2017 to 2019

\begin{tabular}{|l|l|l|l|}
\hline Project & 2017 & 2018 & 2019 \\
\hline $\begin{array}{l}\text { Net cash flows from } \\
\text { operating activities }\end{array}$ & 201.33 & -1432.98 & -1627.54 \\
\hline $\begin{array}{l}\text { Net cash flows from } \\
\text { investing activities }\end{array}$ & -1198.54 & -3142.12 & -1269.33 \\
\hline $\begin{array}{l}\text { Net cash flows from } \\
\text { financing activities }\end{array}$ & 865.27 & 3400.54 & 2411.03 \\
\hline
\end{tabular}

Sources: The author sorted out by herself

In 2017, the net cash flow generated by financing activities of $\mathrm{Q}$ enterprise could basically meet the expenditure of operating activities and investment activities. However, from 2018 on, the cash flow of financing activities was basically far less than the overall expenditure of operating activities and investment activities. The operation then was relatively difficult, and the capital chain suffered the risk of rupture. 24

Table 2: Current assets, current liabilities and working capital of Q enterprise from 2017 to 2019

\begin{tabular}{|l|l|l|l|}
\hline Project & 2017 & 2018 & 2019 \\
\hline Current assets & 3746 & 5967 & 6132 \\
\hline Current liabilities & 864 & 3420 & 3551 \\
\hline Working capital & 2257 & 1888 & 748 \\
\hline
\end{tabular}

Sources: The author sorted out by herself 
Table 3: Change of working capital of Q enterprise from 2017 to 2019

Unit: Ten thousand Yuan

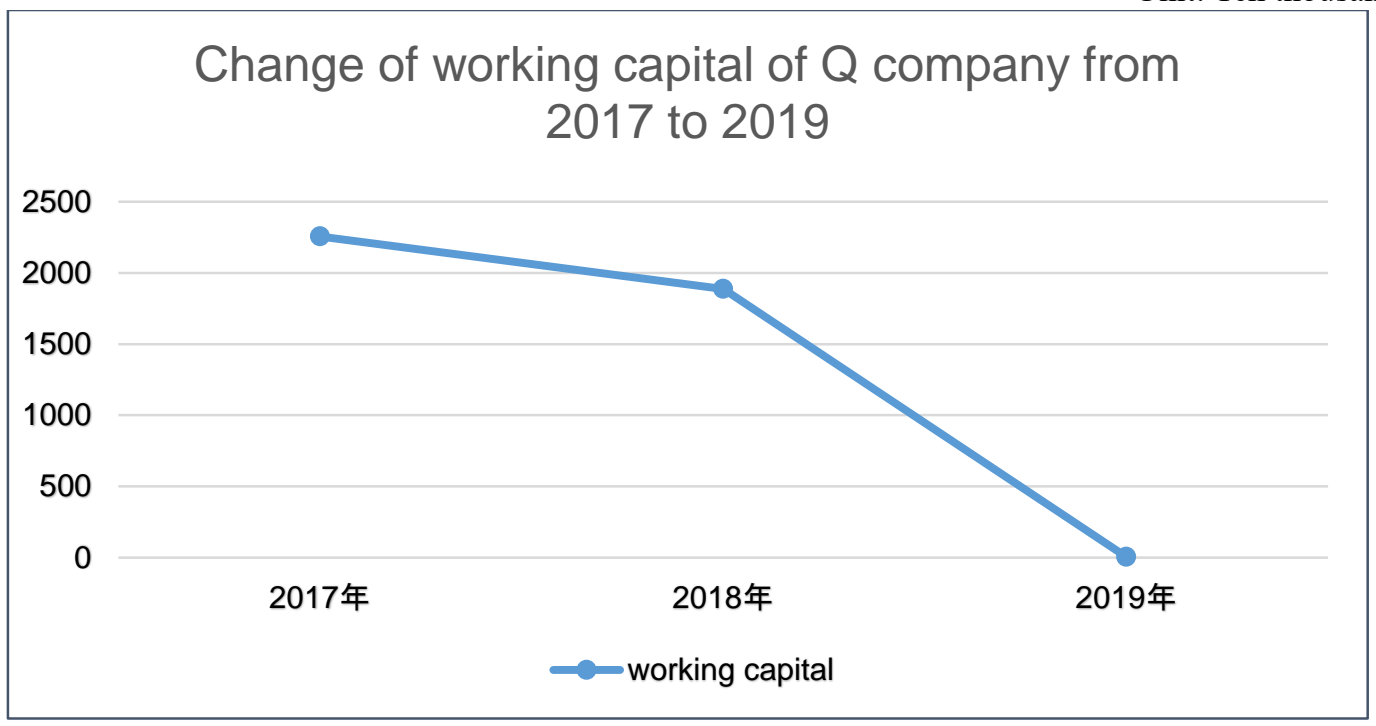

Sources: The author sorted out by herself

From 2017 to 2019, current assets and liabilities of Q enterprise were in an upward trend, but its working capital continued to decline faster, which shows its decreased solvency to short-term debts and that it is necessary to supplement working capital in time to maintain the operation of the enterprise. they must meet very harsh conditions and bear higher interest rates. However, China's indirect financing channels are not well-developed with imperfect relevant laws and regulations. The enterprise could not manage to obtain funds by issuing stocks and bonds, so the main external financing comes from bank loans.

\subsubsection{Status of external financing}

Q enterprise belongs to SMEs. Due to insufficient credit and other reasons, even if they borrow from banks,

Table 4 Proportion of main short-term liabilities of Q enterprise

\begin{tabular}{|c|c|c|c|c|c|c|}
\hline Project & \multicolumn{2}{|c|}{2017} & \multicolumn{2}{|c|}{2018} & \multicolumn{2}{|c|}{2019} \\
\hline $\begin{array}{l}\text { Short-term } \\
\text { loans }\end{array}$ & 357 & $41.32 \%$ & 2100 & $61.40 \%$ & 1968 & $55.42 \%$ \\
\hline $\begin{array}{l}\text { Accounts } \\
\text { payable }\end{array}$ & 302 & $34.95 \%$ & 410 & $11.99 \%$ & 640 & $18.02 \%$ \\
\hline $\begin{array}{l}\text { Advance } \\
\text { collection }\end{array}$ & 205 & $23.73 \%$ & 376 & $11.00 \%$ & 609 & $17.15 \%$ \\
\hline $\begin{array}{l}\text { Other } \\
\text { payables }\end{array}$ & 127 & $14.70 \%$ & 534 & $15.61 \%$ & 334 & $9.41 \%$ \\
\hline Total & 864 & & 3420 & & 3551 & \\
\hline
\end{tabular}

Sources: The author sorted out by herself

As can be seen from Table 1-4, in the past three years, the external financing of $Q$ enterprise has mainly depended on short-term loans from banks, but all these short-term loans require part of machine tools, spare parts, raw materials and a small number of products of the enterprise as pledge. In 2018, enterprises could use various assets as pledge to get larger loan from banks. In 2019, as the fixed assets that could be used as pledge 
became fewer, banks would lower the loan limit accordingly.

\subsection{Financing process of accounts receivable of $Q$ enterprise}

\subsubsection{Internal evaluation of enterprise}

Before the financing of accounts receivable, Q enterprise will evaluate and count the existing accounts receivable, classify them according to the accounts' age, screen out the ones with the account age less than 90 days, and analyze the debtors of corresponding accounts receivable, including their past credit level, solvency, operating status, etc., to further select the accounts receivable suitable as pledge.

\subsubsection{Accounts receivable financing}

Table 5 Data related to accounts receivable of Q enterprise from 2017 to 2019

Unit: Ten thousand Yuan

\begin{tabular}{|l|l|l|l|}
\hline Year & 2017 & 2018 & 2019 \\
\hline $\begin{array}{l}\text { Accounts } \\
\text { receivable }\end{array}$ & 937 & 1432 & 1512 \\
\hline $\begin{array}{l}\text { Current } \\
\text { assets }\end{array}$ & 3746 & 5967 & 6132 \\
\hline $\begin{array}{l}\text { Accounts } \\
\text { receivable } \\
\text { /current } \\
\text { assets }\end{array}$ & $25 \%$ & $24 \%$ & $25 \%$ \\
\hline
\end{tabular}

Sources: The author sorted out by herself

As can be seen from Table 1-5, in the past three years, due to the continuous expansion and increased sales volume of products, the amount of accounts receivable and current assets of $Q$ enterprise has been upward. The ratio of accounts receivable to current assets was basically stable, and the amount of accounts receivable was relatively large, indicating that they are an important asset and the enterprise met the conditions for accounts receivable financing.

Table 6 Data related to accounts receivable financing of Q enterprise from 2018 to 2019

Unit: Ten thousand Yuan

\begin{tabular}{|l|l|l|}
\hline Project & 2018 & 2019 \\
\hline $\begin{array}{l}\text { Financing limit of } \\
\text { accounts receivable }\end{array}$ & 700 & 965 \\
\hline Short-term loans & 2100 & 1968 \\
\hline
\end{tabular}

\begin{tabular}{|l|l|l|}
\hline $\begin{array}{l}\text { Accounts receivable } \\
\text { financing limit }\end{array}$ & $33.34 \%$ & $49.03 \%$ \\
/short-term loans & & \\
\hline
\end{tabular}

Sources: The author sorted out by herself

Starting from 2018, Q enterprise began to use accounts receivable as pledge of financing to obtain funds, with a term of one year. As can be seen from Table 1-6, the amount of accounts receivable financing of $\mathrm{Q}$ enterprise is in an upward trend, which is consistent with the trend of the amount of accounts receivable. In addition, the proportion of funds raised through shortterm loans is reduced, which indicates that $\mathrm{Q}$ enterprise has adopted accounts receivable financing more often.

\subsection{Analysis of financing effect of accounts receivable and suggestions for operations}

\subsubsection{Effect analysis}

Although the operating capital of Q enterprise has gradually decreased since 2017 and a shortage of funds occurred, the operation has improved to a certain extent by 2019 thanks to the reasonable utilization of accounts receivable, which has had a great impact on the development as follows:

Table 7 Year-on-year growth rate of assets and income

\begin{tabular}{|l|l|l|l|l|}
\hline Project & \multicolumn{2}{|c|}{2018} & \multicolumn{2}{c|}{2019} \\
\hline $\begin{array}{l}\text { Current } \\
\text { assets }\end{array}$ & 5967 & $59.29 \%$ & 6132 & $2.77 \%$ \\
\hline $\begin{array}{l}\text { Total } \\
\text { assets }\end{array}$ & 12437 & $66.13 \%$ & 15689 & $26.15 \%$ \\
\hline $\begin{array}{l}\text { Operating } \\
\text { income }\end{array}$ & 986 & $14.13 \%$ & 1145 & $16.12 \%$ \\
\hline
\end{tabular}

Sources: The author sorted out by herself

According to the data in Table 1-7, the current assets of enterprise Q increased by 59.29\% year-on-year from 2017 to 2018 , and the total assets increased by about twothirds year-on-year. At the same time, the operating income also improved to a certain extent, with a $14.13 \%$ year-on-year increase compared with 2017. In 2019, the growth rate of $\mathrm{Q}$ enterprise decreased, but the growth trend remained unchanged. Current assets increased by $2.77 \%$ year-on-year, and total assets increased by about a quarter year-on-year. Operating income increased by $16.12 \%$ year-on-year. It can be seen from this that $Q$ enterprise has activated its large amount of accounts receivable after adopting this method, and then solved the financing problems so as to sustain the operation. 


\section{DISCUSSION ON THE DEVELOPMENT AND INFLUENCE OF ACCOUNTS RECEIVABLE FINANCING DURING COVID-19}

In 2020, the COVID-19 broke out in Wuhan and spread rapidly to the whole country and even the world. The epidemic not only caused harm to people's health, but also brought heavy damage to the national economic operation. In particular, various financing activities, including accounts receivable financing, bank loans, etc., have been greatly impacted, but the development of accounts receivable financing has not completely stagnated.

In order to carry SMEs through the difficulties, the Ministry of Industry and Information Technology has introduced 20 new measures. Among them, the third largest sector stresses further financial supports for SMEs, clearly indicating that China should increase credit support, strengthen financing guarantee services and innovate financing products and services. 25

The first is to increase credit support for SMEs. The loan interest rate of SMEs will be appropriately lowered and long-term loans will be available. For those who are difficult to repay the loan, they can be allowed to extend or renew the loan. However, this policy is not aimed at all SMEs, but mainly supports some SMEs that own bright prospects and good operation but are affected by the epidemic and encounter difficulties in operation and financing. 26

The second is to strengthen financing guarantee services. It is necessary to encourage financing guarantee from government-level and re-guarantee institutions at all levels to improve the efficiency of business. It is also needed to erase counter-guarantee requirements, and reduce the charge rates of guarantee and re-guarantee. Government-level financing guarantee institutions at all levels that provide financing guarantee services for SMEs that do not have solvency, shall compensate the debts in due time, appropriately extend the time of debt collection considering the influence of the epidemic, and cancel the compensation amount after verification for those eligible according to the regulations. 27

Finally, it turns to innovating financing products and services. The need has been specified to promote the accounts receivable pledge financing, actively build an online bank-enterprise coordinating platform, improve the efficiency of information exchange, and speed up the grant of loan.

To sum up, although the outbreak of the COVID-19 has threatened SMEs with weak capital accumulation, to a certain extent it has also drawn our government's attention to other financing methods, and then pushed the development of accounts receivable financing.

\section{CONCLUSION}

In China, accounts receivable financing has not been fully developed and promoted. There exist some problems no matter in the formulation of relevant laws and regulations, or in management and supervision. In order to promote the process of accounts receivable financing and broaden the financing channels of SMEs, it requires the joint efforts of the government and enterprises.

The conclusions and suggestions are as follows:

\subsection{The enterprise shall establish a joint management system for accounts receivable}

The management of accounts receivable is not only a matter for the financial department. It should be a project that requires the whole enterprise to cooperate and manage. As the market becomes increasingly saturated, some companies, in order to occupy the market as soon as possible, link the salary of sales personnel to the sales volume of their products, and only by selling more can they get higher wages. But the reality is that the company's sales have increased, but the cash flow has not, with a significant increase in the accounts receivable. The more accounts receivable an enterprise has, the more funds are occupied by customers. Customers obtain free commercial credit financing through accounts receivable, but the company must pay for this cost. Once the customers miss the due time or turns accounts receivable into bad debts because of major incidents or something, the enterprise would suffer fund loss and increasing pressure from repayment and operating cost, which is detrimental to the future sustainable development. 28

Therefore, enterprises should establish a joint management system of accounts receivable, and different departments should do their parts together to supervise and manage the transaction process. For example, when the sales department sells each product, it should evaluate the solvency of the customer in advance, and count the sources of each selling amount. When the enterprise prepares for the financing of accounts receivable, the department should screen out the accounts receivable with higher amount and diversified debtors. Enterprises should pay attention to the financing value of accounts receivable, strictly conduct the operation and audit of each part, and make full preparations for accounts receivable pledge. 


\subsection{Long-term cooperative relationship with financing institutions}

To conduct accounts receivable financing business, the borrower and the lender need to collect information and analyze financial situation of each other. Establishing a long-term cooperative relationship with financing institutions, first of all, can turn one game into multiple games, and both sides become mutually beneficial and win-win partners, instead of participants of gambling making quick cash. Long-term cooperation allows both enterprises and financing institutions to avoid fraud, default and other acts. Secondly, with continuous cooperation and exploration, financial institutions will also deepen their understanding of the enterprise's management system, financial situation, business strategy, etc. By doing this, a large amount of manpower, resources and money used to evaluate the other party can be greatly saved. 29

To sum up, the accounts receivable financing has a bright prospect, deserves promotion, and plays a decisive role in solving the financing difficulties of SMEs. However, it has not gained enough publicity and sufficient support from relevant laws and regulations as well as the government. To promote the development of accounts receivable financing, the joint efforts of law, government and enterprises are required.

\section{REFERENCES}

[1] Chen Lei. Analysis on Financing Dilemma of SMEs Based on Asymmetry Information Perspective. Review of Investment Studies, 2011(10): 58-63.

[2] Chi Guohua. The Whole-process Management Mode of Corporate's Accounts Receivable in Credit Economy. Management World, 2009(06): 176-177.

[3] Cui Xuegang, Yang Yanyan. Research on Financing Demand and Capital Structure Choice of SMEs in China-An Empirical Test on Small and Mediumsized Listed Companies. Journal of Beijing Technology and Business University (Social Sciences Edition), 2008(06): 58-66.

[4] Dong Xiaoling. Difficulties and Countermeasures of Chinese SMEs financing. Capital Operations, 2013(29): 39-40.

[5] Gang Hao, Tang Xiao Wo, Mu Yinping. Research on Supplier's Optimal Operation Strategy and CoOrdination under Delay in Payment Considering Setting Account Receivable Ratio. Journal of Industrial Engineering and Engineering Management, 2014,28 (02): 114-119.
[6] Ge Liwei, Duan Weiming, Zhang Fang, Wu Zhongming. Defects in Legislation of Registration of Pledge Receivables. Financial Forum, 2008(02): $18-25$.

[7] Ministry of Industry and Information Technology. Notice on Responding to the COVID-19 Epidemic and Supporting Small and Medium-sized Enterprises in Resuming Work and Production and Overcoming Obstacles. Uncoded Telegram of MIIT (2020) No. 14, February 9,2020.

[8] Guo Lihong, Xu Xiaoping. The Determinants of SMEs' Financing Constraints. South China Journal of Economics, 2012(12): 36-47.

[9] Guo Mingrui. Three Questions about the Pledge of Accounts Receivable. Jianghuai Tribune, 2011(06): 81-87.

[10] Guo Na. Government? Market? Who is More Effective to Solve SMEs' Difficulties in Financing? Journal of Financial Research, 2013(03): 194-206.

[11] Guo Tao. New Financing Channels for SMEs. China Economist. 2005(02): 152-153.

[12] Han Guowei. Research on the Innovative Mode of Accounts Receivable Financing of SMEs. Financial Horizon, 2012(01): 150-153.

[13] Jiang Jinsong. Thinking on the Management Mode of Accounts Receivable of Enterprises in China. Journal of Shanxi University of Finance and Economics, 2011,33 (S4): 49-50+87.

[14] Jin Huanyang. Risk Management in Accounts Receivable Financing of SMEs--A Case Study on Wenzhou Commercial Bank. Research on Development, 2011(03): 130-132.

[15] Li Yunchao. Resolve the Financing Bottleneck of SMEs from the Perspective of Insurance. Enterprises Accounting, 2014(05): 169-170.

[16] Lin Li. On the Financial Preference of SMEs and the Optimizing Strategy of Capital Structure. Journal of Sichuan Normal University (Social Sciences Edition), 2013,40 (04): 74-79.

[17] Liu Dianying. A Preliminary Analysis of the Causes of Account Receivable Risks and Preventive Measures. Modern Business, 2011(26): 92-94.

[18] Wang Qichang, Long Yuan. Receivable Financing: One Way to Settle Financing Difficulty of SMEs. Collected Essays on Finance and Economics, 2007(3): 43-46.

[19] Wang Jie, Qiao Xianglan. China's SME Financing 
Difficulties and Countermeasures. China Business and Market, 2013(10): 123-124.

[20] Wu Xiaojun. An Empirical Study on the Impact of Local Government Policies on the Financing Cost of SMEs. Public Finance Research, 2013(09): 53-56.

[21] Xu Xinyan. The Typical Forms and Risk Prevention of Accounts Receivable Financing. Zhejiang Finance, 2009(08): 26-27.

[22] Xu Shengdao, Han Xueguang, Xu Haoran. Financial Gap, Financial Innovation: Theoretical Explanations and Countermeasures Analysis of Financing Difficulty of SMEs. Financial Theory and Practice, 2011(04): 17-21.

[23] Yin Mengbo, Xu Kun, Qiu Yu. An Analysis Based on Adverse Selection Mechanism for SME Finance: Asymmetric Information between Banks and SME under the Principal -Agent Model. Finance \& Economics, 2011(11): 61-69.

[24] Yu Jianmei. To Ease the Financing Difficulties of SMEs by Supply Chain Finance. Economic Review, 2011(03): 99-102.

[25] Zhang Guoming, Li Cunying. Research on the Internal Control Methods of Enterprise's Accounts Receivable. Research of Financial \& Accounting, 2011(24): 60-62.
[26] Zhang Huifeng, Cao Pu. Accounts Receivable Financing: The Most Effective Financing Model for Small and Medium Movie Production Firms in China. Journal of International Communication, 2014(01): 114-117.

[27] Zhang Wenqiang. The Risk and Pricing of Securitization of Accounts Receivable Assets of Entity Enterprises. Journal of Financial Research, 2009(05): 194-206.

[28] Zheng Zhongliang, Bao Xing. A Research on Check Rate and Punishment Mechanism of Accounts Receivable Mode in Supply Chain Finance. Economic Review, 2014(06): 149-158.

[29] Zhou Ying, Li Pu. Study on Financing Arrangement of ARBS. Journal of Central University of Finance \& Economics, 2007(02): 92-94.

[30] Zhou Yuanyuan. Research on the Accounts Receivable Pledge Financing. Journal of Regional Financial Research, 2012(02): 4-7.

[31] Zhang Guoming, Li Cunying. Research on the Internal Control Methods of Enterprise's Accounts Receivable. Research of Financial \& Accounting, 2011(24): 60-62.

[32] Zhang Yukou. Brief Analysis of the Connotation and Thinking of Accounts Receivable Management. China Business \& Trade, 2012(14): 58-59. 